\title{
Seismic communication between the burrows of kangaroo rats, Dipodomys spectabilis
}

Accepted: 13 May 1997

\begin{abstract}
Banner-tailed kangaroo rats, Dipodomys spectabilis, footdrum to produce substrate-borne and airborne acoustic energy. Previous studies show that they communicate territorial ownership via airborne footdrumming signals. The research reported here used simulated footdrum patterns generated by an artificial 'thumper' to address the question of whether kangaroo rats communicate through seismic components of these acoustic signals. With microphones suspended in sealed burrows, we found that airborne sounds were attenuated by approximately $40 \mathrm{~dB}$ as they passed through the burrow wall into the burrow chamber. The substrateborne vibrations from the thumper yielded sound approximately $40 \mathrm{~dB}$ greater in peak amplitude than the attenuated airborne sound. Thus, $99.9 \%$ of the peak power of the thumper was transmitted directly through the substrate into the burrow. The rats in sealed burrows timed their responses to playbacks of footdrums from the thumper and a loudspeaker so they did not initiate a drumming sequence during either the seismic or airborne signals. When these signals were masked by loud noise, the rats continued to drum to the seismic signal but drummed randomly during the airborne playback. These results suggest that the sealed burrow provides a quiet place in which $D$. spectabilis can listen for substrate-borne communications from conspecifics.
\end{abstract}

Key words Kangaroo rat · Footdrum - Seismic Communication $\cdot$ D. spectabilis

Abbreviations $S P L$ sound pressure level

\footnotetext{
J.A. Randall ( $\square)$

Department of Biology, San Francisco State University, San Francisco, CA 94132, USA

Fax: + 1-415 338-2295

e-mail: jrandall@sfsn.edu

E.R. Lewis

Department of Electrical Engineering

and Computer Sciences, University of California,

Berkeley, CA 94720, USA
}

\section{Introduction}

There are two obvious channels for transmission of acoustic energy in terrestrial animals: the air and the substrate. When the airborne channel is filled with acoustic noise, the substrate or seismic channel may provide a relatively noise-free alternative for transmission of signals to remote locales.

A wide variety of terrestrial animals create seismic signals by mechanically rubbing, tapping, drumming or banging parts of the body on a substrate. As a result, a substantial portion of the resulting acoustic energy is transmitted in the seismic channel rather than in the air (Markl 1983; Narins et al. 1992; Randall 1993). Some of these animals have structures specialized for sensing the seismic vibrations; in a few cases, there is evidence that the animals use the seismic channel for intraspecific communication (Koyama et al. 1982; Pratte and Jeanne 1984; Narins 1990; Heth et al. 1991; Baurecht and Barth 1992; Narins et al. 1992). Among terrestrial vertebrates, evidence for communication is limited to white-lipped frogs, Leptodactylus albilabris, that thump the ground with their vocal sacs to generate vibrations in the soil (Lewis and Narins 1985; Cortopassi and Lewis 1992) and to two fossorial mole-rat species. Spalax ehrenbergi drums its head on the top of the burrow (Heth et al. 1987; Rado et al. 1987, 1989) and Georychus capensis drums its feet on the burrow floor (Jarvis and Bennett 1991; Narins et al. 1992).

Banner-tailed kangaroo rats, Dipodomys spectabilis, interact by footdrumming. These nocturnal, desert rodents drum a complex pattern of individual footdrumming signatures that they can discriminate as originating from a neighbor or a stranger (Randall 1984, 1989, 1993, 1994a). When presented with the sound of footdrums, either generated directly by another rat or recorded previously by an experimenter and played through a loudspeaker, a rat typically responds with footdrums of its own (Randall 1984, 1994a, 1995). In footdrumming exchanges, each rat tends to begin its own drumming 
pattern when the other rat is not drumming. The consistency of response to footdrumming played through a loudspeaker and field observations show that interactions between two rats involve airborne sound (Randall 1984, 1994a).

D. spectabilis footdrums almost exclusively on territories consisting of large dirt mounds, approximately 2 $3 \mathrm{~m}$ in diameter, in which the rats store large caches of seeds, their main food source (Randall 1984). Each mound is defended by a single animal of either sex, except when young rats are in natal mounds with mothers (Randall 1984). The kangaroo rats drum on the surface of the mound or on the floor of the burrow chamber inside the mound (Randall 1984, 1993). When inside the mound for any length of time, the rats typically seal the burrow entrance with several centimeters of dirt. When a mound caves in, its height is reduced to the level of the surrounding ground to suggest that the volume of the mound is equal to the volume of the rat's chamber directly beneath it.

Although evidence for footdrumming in territorial communication is strong for D. spectabilis, the question remains whether these semi-fossorial animals use the seismic channel to communicate (Narins 1990). Footdrumming produces considerable substrate-borne acoustic energy (easily detected with geophones) as well as airborne acoustic energy. The rats often footdrum from inside their mounds when the airborne channel seems unusable or unused. In two instances, using geophones to monitor footdrums from the floors of the sealed chambers of neighboring rats whose mounds were approximately $10 \mathrm{~m}$ apart, J.A. Randall (unpublished observations) heard rats exchanging footdrums between burrows, despite strong winds over the surface of the ground that in one case rendered the airborne footdrums inaudible to the human observer. We doubted that the airborne sounds, attenuated by passing twice from air through burrow walls, could have been effective communication signals. Therefore, we considered it likely that the footdrumming was transmitted between burrows through the substrate, in the seismic mode, from one burrow to the other.

Our research addressed the effectiveness of transmission of footdrumming signals into a sealed burrow. Can the kangaroo rats really sense the seismic component of the drumming? We performed both behavioral and physical experiments to answer this question. We designed behavioral experiments to test whether a rat in a burrow chamber responds to artificial footdrums when the airborne sounds of the drums are masked by highamplitude noise (sound comprising random fluctuations of the instantaneous sound pressure). We designed the physical experiments to determine the relative amplitudes of acoustic signals transmitted to the burrow through the air and through the substrate. We hypothesized that, despite poor acoustic conditions for sound transmission through the air outside the burrow, the rats could listen for substrate-borne (seismic) footdrums in the quiet acoustic environment provided by a burrow chamber.

\section{Materials and methods}

Study site and subjects

We conducted tests in June 1990, from 1 to 10 August 1991, and in August 1992 on a 3.6-ha $(150 \times 240 \mathrm{~m})$ study site that was established by J. Randall in 1980 approximately $7 \mathrm{~km}$ northeast of Portal, Arizona (Randall, 1989, 1994a, 1995). Active mounds were identified and numbered with stakes and plastic flags, and distances between neighboring mounds measured with a $100-\mathrm{m}$ tape.

Population densities in 1990 were the highest in 8 years, and $80 \%$ of the mounds on the study site were occupied with a total of 40 animals an average of $18 \mathrm{~m}$ apart. Densities declined in 1991 to 19 animals averaging $33 \mathrm{~m}$ apart and reached a low in 1992 with only 14 animals present at $41 \mathrm{~m}$ apart. We increased the number of animals available for testing in 1991 by expanding the site to the west of the original study site to include 10 animals.

\section{Generation of seismic drumming}

We generated seismic footdrumming for both physical and behavioral experiments with a mechanical 'thumper' designed to simulate the footdrums of a drumming rat (Fig. 1). The thumper consisted of a striking device from an electric typewriter which was mounted on an aluminum box to strike a pad consisting of a small aluminum disk sandwiched between two rubber sheets in direct contact with the ground beneath the thumper. The mass of the thumper was increased by mounting its power source (a $12-\mathrm{V}$ leadacid battery) inside the aluminum box. An electronic pulse generator triggered from a tape recording of a rat's footdrumming pattern drove the thumper.
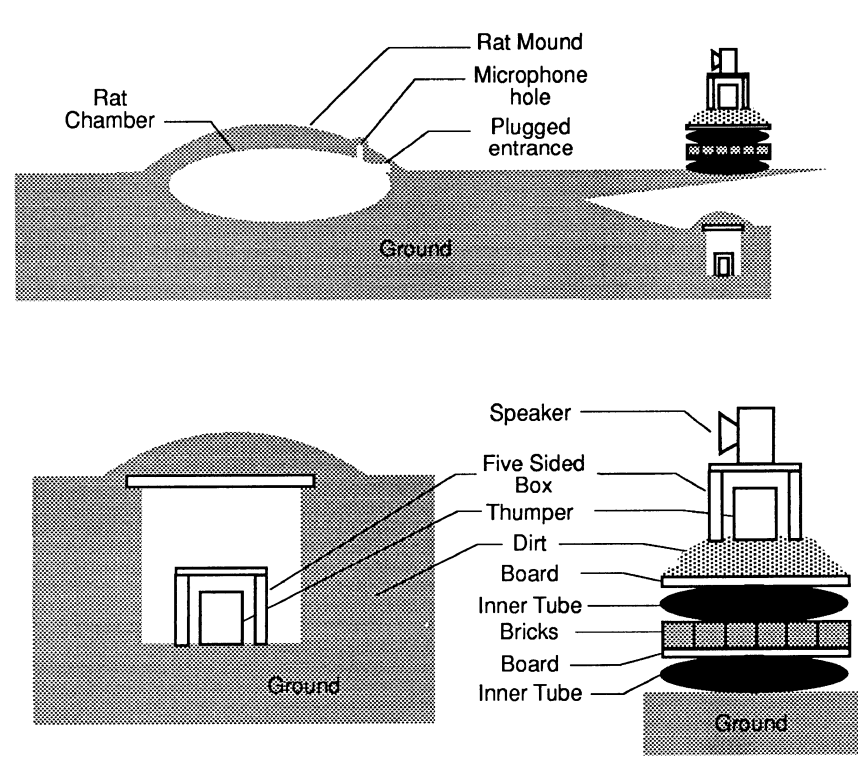

Fig. 1 Configuration of sound transmission tests showing rat chamber with position of the microphone in proximity to the buried thumper and thumper and speaker on a vibration-isolation platform. Enlargements are of the thumper and its position in the ground and on the vibration-isolation platform 
Physical measurements

The physical experiments were designed to determine: (1) the amount of attenuation provided by the burrow wall for airborne sounds, and (2) whether that attenuation is circumvented by the substrate-borne (seismic) footdrums. This design provided a direct physical test of our hypothesis that the rats use the sealed burrow chambers as quiet places in which they can listen for footdrumming.

We measured the sound inside each of three rat burrow chambers by suspending a microphone in a vertical hole drilled in the chamber ceiling. (Rats occupied the burrow chamber in all three tests, and the entrance hole was plugged.) We used small electret microphones (Realistic model 33-1052) with good frequency characteristics (nearly flat response from 50- to $20000 \mathrm{~Hz}$ ) for all sound measurements in the burrow chamber. Each microphone was tested in the lab for sensitivity to substrate vibrations by mounting it on a vibration table driven by a Bruel \& Kjaer 4810 minishaker. Responses were observed over the frequency range of the minishaker and found to be below the microphone noise floor until the vibration amplitudes were increased sufficiently to yield audible airborne sound. At that stimulus level, the responses of the microphones were the same when placed immediately above the table and isolated from the table vibrations as when mounted directly on the table. Thus, the microphone response at each frequency was attributable entirely to the airborne sound component.

We drilled vertical holes into the mound through the ceiling of the burrow chamber with a $1.27-\mathrm{cm}$ masonry bit. The wall over the chamber at the site of the hole drilled for the microphone was approximately $12 \mathrm{~cm}$ for the first and third chamber and $5 \mathrm{~cm}$ for the second. We suspended the microphone at the bottom of the drilled hole, sealed the entrance to the hole with a small rock and covered it with a small mound of dirt. This configuration was repeated for all three burrow chambers.

In the first two burrow chambers, we generated airborne thump sounds with a Minimus-7 speaker on a vibration-isolation platform located $4 \mathrm{~m}$ from the microphone hole and seismic thumps from a buried thumper also positioned $4 \mathrm{~m}$ from the microphone (Fig. 1). Airborne thumps sounds emitted from the buried thumper and from the speaker on the platform were calibrated with a Sennheiser ME88 microphone at a distance of $0.5 \mathrm{~m}$.

We conducted an experiment in a third burrow chamber to measure the effectiveness of the two channels (airborne and substrate-borne) for acoustic energy generated by thumping on the substrate. We generated seismic thumps by tapping on the ground $2.3 \mathrm{~m}$ from the drilled microphone hole and $1.8 \mathrm{~m}$ from the edge of the mound at approximately $1 \mathrm{tap} / \mathrm{s}$ with a rubber mallet. To provide nearly identical airborne sound without accompanying seismic components, the sound of the rubber mallet tapping the ground was recorded on the Marantz cassette recorder and played on another cassette recorder (Aiwa HS-G370) through the speaker, which was mounted on the vibration-isolation platform $2.5 \mathrm{~m}$ from the microphone hole. We used a rubber mallet, instead of the mechanical thumper, because the amplitude of the thumper could not be adjusted and the metal box on which the striker was mounted added high-frequency airborne sound components. The mallet allowed us to adjust the amplitude of the thumps, and the fast footdrumming of the rats emitted by the thumper was unnecessary for the physical measurements. A small piece of plywood, $2.54 \mathrm{~cm}$ thick, was placed over the sealed microphone hole, and a second, identical microphone was placed on top of the board, allowing us to record the sound of each thump simultaneously inside and outside the chamber at each end of the drilled hole.

We also constructed a simulated rat chamber, consisting of a cube-shaped excavation approximately $0.6 \mathrm{~m} \times 0.6 \mathrm{~m} \times 0.6 \mathrm{~m}$ in the flat ground and measured the sound inside with a microphone sealed into the chamber. We suspended the microphone inside the artificial burrow on a vibration-isolation filter comprising three compliant springs and three lead fishing weights to produce a sixpole, low-pass filter with a corner frequency of approximately $1 \mathrm{~Hz}$ for each octave above that frequency. We covered the burrow with a plywood board and piled a mound of the soil approximately
$12 \mathrm{~cm}$ thick onto the board and placed a matching microphone on the dirt that covered the chamber. Thumps were generated by tapping lightly on the ground with a rubber mallet or fingers. We generated airborne thump sounds as before by recording the thump sounds with a microphone and playing them through the speaker. Airborne noise sound also was presented from the speaker.

\section{Behavioral experiments}

We tested adult kangaroo rats and dispersed juveniles living in separate mounds for their responses to playbacks designed to separate responses to the airborne and seismic signals. We tested a total of 6 animals ( 2 females and 4 males) in 1990 and 16 (10 males and 6 females) in 1991. To simulate the footdrum pattern for the behavioral experiments, a tape recording of a drumming rat triggered the thumper electronically so that it replicated each individual thump in the rat's pattern. Playbacks consisted of a 31-s tape loop continuously playing two $D$. spectabilis footdrumming bouts. The first and longest bout occurred in seconds $1-4$ with the second bout beginning in second 19 and ending in second 21. The two bout, therefore, consisted of $7 \mathrm{~s}$ of playback drumming and $24 \mathrm{~s}$ of no drumming.

We tested the rats for their responses to seismic and airborne footdrumming in three steps. We presented:

1. Simultaneous seismic footdrums from the mechanical thumper buried in the ground and high-amplitude noise broadcast through a loudspeaker to mask the airborne sound from the buried thumper.

2. Airborne footdrumming without the seismic components and without noise from the loudspeaker.

3. Simultaneous presentation of the airborne thump sounds from a vibration-isolation platform (without seismic components) and high-amplitude noise as a control to verify that the high-amplitude noise masked any airborne sound. The noise presented in step 1 had the same amplitude and spectral composition as that presented in step 3. In each case, the noise source (loudspeaker) was placed directly on top of the source of the thump sounds, so that the azimuths of the thump sounds and noise were the same relative to the subject rat.

Our goal in the seismic tests in step 1 was to produce seismic footdrumming vibrations while masking any airborne sound. We first reduced the amplitude of the airborne sound produced by the mechanical thumper by burying it in a hole $30 \mathrm{~cm}$ deep and covering it with a plywood box which we covered with a mound of soil (Fig. 1). We played the high-amplitude, masking noise from a speaker placed on top of the mound of soil. This noise was recorded with a spectral compensation to make the playback flat from approximately 40 to $15000 \mathrm{~Hz}$ when presented through the speaker used in these studies. The noise level typically had a rootmean-square amplitude 30-40 dB louder than the thump sounds generated by the buried thumper.

We positioned the buried thumper adjacent to the edge of the mound at a distance of $4 \mathrm{~m}$ from the rat's sealed entrance hole. One of us monitored the footdrumming pattern generated by the thumper with a vertical geophone in a hole between the thumper and the mound to adjust pattern output. The other recorded the rat's footdrumming with another vertical geophone placed directly on the surface of the mound near the burrow entrance, which is the best place to obtain good recordings of rats footdrumming inside the mound (Randall 1989, 1995).

Our goal in step 2 was to transmit airborne footdrumming to the rat without a seismic component. For consistency, we wanted to transmit airborne sound with a mechanical thumper identical to the buried one. We therefore placed a mechanical thumper on a mound of dirt on the vibration-isolation platform and covered it with a plywood box identical to that covering the buried thumper (Fig. 1). Because the rats did not respond well to the airborne sounds from the thumper, and we knew from prior studies that they responded to airborne footdrumming from a speaker (Randall 1984, 1994a; Randall and Matocq, in press), we broadcast the airborne footdrumming from a speaker on the vibration-isolating 
platform for most of the experiment. The peak amplitude of the airborne sound generated from the platform was approximately $20 \mathrm{~dB}$ higher than that generated by the buried thumper, and the platform served to attenuate the ground-borne vibrations from the thumper by more than $60 \mathrm{~dB}$. We recorded footdrumming responses of the rat with geophones as in step 1.

For the control in step 3, we combined step 2 with the masking noise from step 1 to show that the masking noise was of high enough amplitude to mask any airborne sound. We usually began the high-amplitude noise after the rat had begun to footdrum in response to the airborne sound to verify that the rat heard the airborne footdrumming.

We used a Sennheiser ME88 directional microphone with flat frequency response from 75 to $14000 \mathrm{kHz}$ to calibrate the airborne sounds produced by the buried thumper, and the thumper and speaker on the isolation platform. The low amplitude of the sounds from the buried thumper usually required calibration at a distance of $0.5 \mathrm{~m}$ from the sound source, rather than at a common point over the rat mound. The responses from geophones and the microphone (for sound calibration) were recorded on a Marantz model PMD 430 two-channel cassette recorder and on a Sony Professional WM-D6 two-channel cassette recorder. Noise stimuli were played through the speaker on an Aiwa cassette player with low-frequency compensation. Footdrumming responses to the playback stimuli were recorded via the geophone on a Uher 4200 or 4000 reel-to-reel recorder.

We analyzed recordings in which we could hear both the playback and the footdrumming response. The repetitive pattern of the thumper and differences in sound quality enabled us to distinguish between the playback and the drumming of the rat in the seismic tests. It was more difficult for us to hear the airborne drumming through the geophones, and we omitted any recordings in which we were unable to hear clearly the playback stimuli.

We scored the time during the 31-s playback when the test subject initiated a footdrumming sequence from the recorded tapes by starting the stopwatch every $31 \mathrm{~s}$ and either writing or checking the time on a data sheet when we first heard a rat begin to footdrum. Later, in the laboratory, we used a computer to count the drums.

\section{Results}

\section{Physical measurements}

Measured outside the burrow chamber, we found that the peak amplitude of airborne thump sounds from the speaker was $27 \pm 1 \mathrm{~dB}$ greater than airborne thump sounds from the buried thumper. Inside the burrow chamber, however, the sound from the thumper had considerably higher amplitude than that from the speaker. Thump sounds from the buried thumper recorded on the microphone suspended in the burrow chamber were $18 \mathrm{~dB}$ above the noise floor of the microphone and were clearly audible to a listener monitoring the microphone output with headphones. The airborne thump sounds from the speaker were sufficiently below the noise floor of the microphone [approximately $50 \mathrm{~dB}$ sound pressure level (SPL)] to be inaudible to the listener. The same result occurred when the airborne thump sounds were generated by the second thumper on the vibration-isolation platform. In the burrow chamber, those sounds were sufficiently below the noise floor of the electret microphone to be inaudible, while the thump sounds from the buried thumper remained audible.
In the second burrow chamber, we measured the effectiveness of transmission of airborne sound into the burrow by increasing the amplitude of the airborne thump sounds from the speaker until they produced a response in the microphone in the burrow chamber that was approximately the same as that produced by the buried thumper. (Subsequent measurement of the recorded peak responses showed that airborne sounds from the speaker actually were $3 \mathrm{~dB}$ greater than those from the buried thumper with both responses in the neighborhood of $60 \mathrm{~dB}$ SPL.) When we calibrated the airborne sounds with the Sennheiser ME88 microphone at a distance of $0.5 \mathrm{~m}$ from each source, we found that the amplitude of the airborne thump sound from the buried thumper was $6 \pm 3 \mathrm{~dB}$ above the noise floor of the Sennheiser. The amplitude of the airborne thump sound from the speaker was $53 \pm 1 \mathrm{~dB}$ above the Sennheiser noise floor making it approximately $47 \mathrm{~dB}$ greater than that from the buried thumper. Thus, transmission into the burrow of acoustic energy from the speaker was approximately $44 \mathrm{~dB}$ less effective than it was from the buried thumper.

We conducted tests in the third rat chamber to verify our results in the first two chambers and found that the peak amplitude of the airborne thump sound from the speaker was $36 \pm 1 \mathrm{~dB}$ greater outside the chamber than it was inside the chamber. Furthermore, at a distance of $2.3 \mathrm{~m}$ from the site of the thump, the peak acoustic power in the sound of the seismic thump was $6 \mathrm{~dB}$ greater inside the chamber than it was outside the chamber at the same location.

Results from the suspended microphone in the simulated burrow chamber matched those from the other three tests. The peak amplitude of the airborne thump sound, without accompanying seismic components, recorded outside the simulated chamber was $36 \pm 1 \mathrm{~dB}$ greater than that recorded inside. The rms amplitude of noise played through the speaker and recorded outside the simulated chamber was $44 \pm 1 \mathrm{~dB}$ greater than that recorded inside. The noise spectrum changed as the sound passed through the chamber wall: the wall tended to pass low frequencies somewhat more readily than high frequencies. Thumps with seismic components were generated (by tapping on the ground) at two distances from the drilled hole $-3 \mathrm{~m}$ and $10 \mathrm{~m}$. From $3 \mathrm{~m}$, the peak amplitudes of the thump sounds recorded inside the chamber and those recorded simultaneously outside were the same (within $1 \mathrm{~dB}$ ). From $10 \mathrm{~m}$, the peak amplitude of the thump sounds recorded in the chamber was $4 \mathrm{~dB}$ less than those recorded simultaneously outside the chamber. These results were the same for both finger tapping and mallet tapping.

With the microphone suspended inside the simulated chamber, we recorded the footdrumming by the rat in the mound nearby. By listening at the mound, we were able to locate the rat within approximately $0.3 \mathrm{~m}$ to make its estimated distance from the simulated chamber $3.3 \mathrm{~m}$. The peak amplitude of the recorded footdrum sounds was approximately equal to $47 \mathrm{~dB}$ SPL. 


\section{Behavioral tests}

D. spectabilis footdrummed to both the seismic and airborne components of the footdrumming signal. Five rats drummed at high rates to all three stimuli. Of these, four rats avoided initiating a drumming sequence during the stimulus of airborne footdrumming presented without noise and to seismic drumming presented with noise. In contrast, the rats drummed randomly during the control when they presumably were unable to hear either a seismic or airborne footdrumming signal (Fig. 2). The fifth rat drummed less consistently, but it also showed a trend similar to the other four. Other rats stopped drumming before enough footrolls were available to quantify their responses to all three stimuli. It was especially difficult to keep rats drumming during the control when they presumably could not hear drumming to stimulate them to drum in return.

Ten rats drummed during the seismic playbacks with airborne noise frequently enough to quantify their drumming responses. When we compared the number of footdrumming sequences initiated during the $7 \mathrm{~s}$ of playback stimuli to the number initiated in the $7 \mathrm{~s}$ before and after the playback, we found that the rats initiated significantly fewer drumming sequences during the seismic playback than either before or after the playback (Freidman: $P<0.02$ ) (Fig. 3). In contrast, similar drumming sequences were initiated before, during, and after the playback stimuli in the five rats that footdrummed during the control $(P=0.53, \mathrm{NS})$.

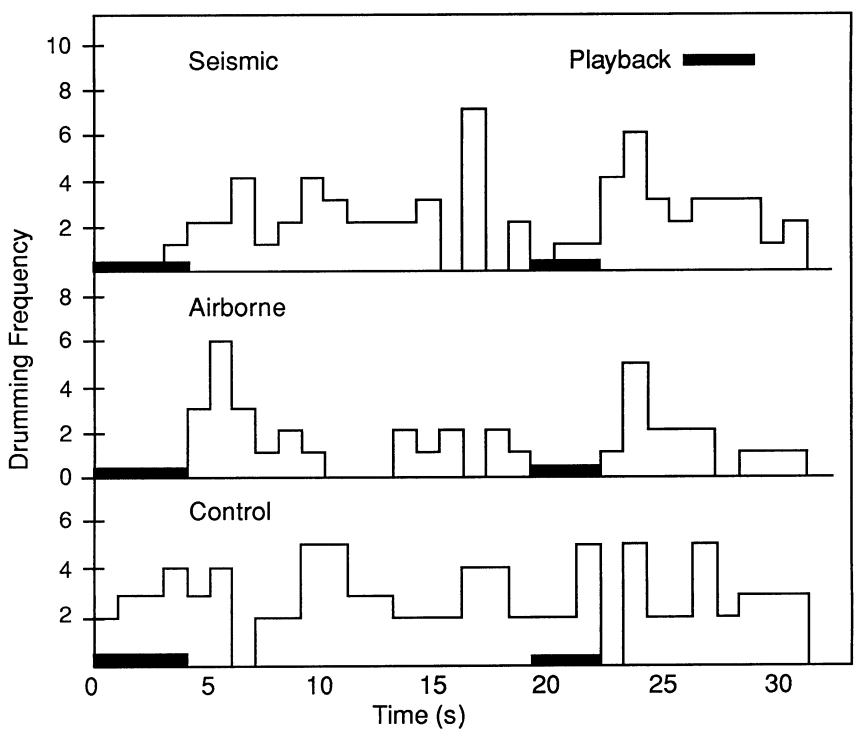

Fig. 2 A typical example of footdrumming responses in adult D. spectabilis to playbacks of footdrumming transmitted seismically underground from a buried thumper with airborne sound masked, through the air from a thumper or speaker on a vibration-reduction platform and a control of airborne sound masked with noise. The dark bars represent the $7 \mathrm{~s}$ during which footdrums were transmitted in a continuous-playing 31-s tape loop. Intervals are quiet

\section{Discussion}

\section{Sound transmission}

Measurements of sound transmission in the rats' burrows strongly suggest that when a thump sound created a seismic vibration, the vast majority of the peak power in the resulting sound in the burrow chamber was transmitted directly through the ground from the site of thumping to the burrow wall and then radiated as airborne sound into the burrow chamber. In the first rat chamber, the peak amplitude of the thump sound in the chamber was increased by at least $18 \mathrm{~dB}$ by the presence of accompanying seismic components, which corresponded to an 80-fold increase in power. Thus, at least $98 \%$ of the peak in the thump sound recorded inside the chamber was transmitted directly through the ground from the thumper to the chamber. The results from the second burrow chamber yielded an even greater amplitude of sound in the burrow. We verified these results with the third burrow chamber. More than $99.99 \%$ of the peak acoustic power in the thump sound recorded inside the rat chamber was transmitted directly through the ground from the site of the thump, and then radiated into the chamber. We conclude that, because the microphone inside the chamber was sensitive to airborne sound but insensitive to vibrations, the acoustic power

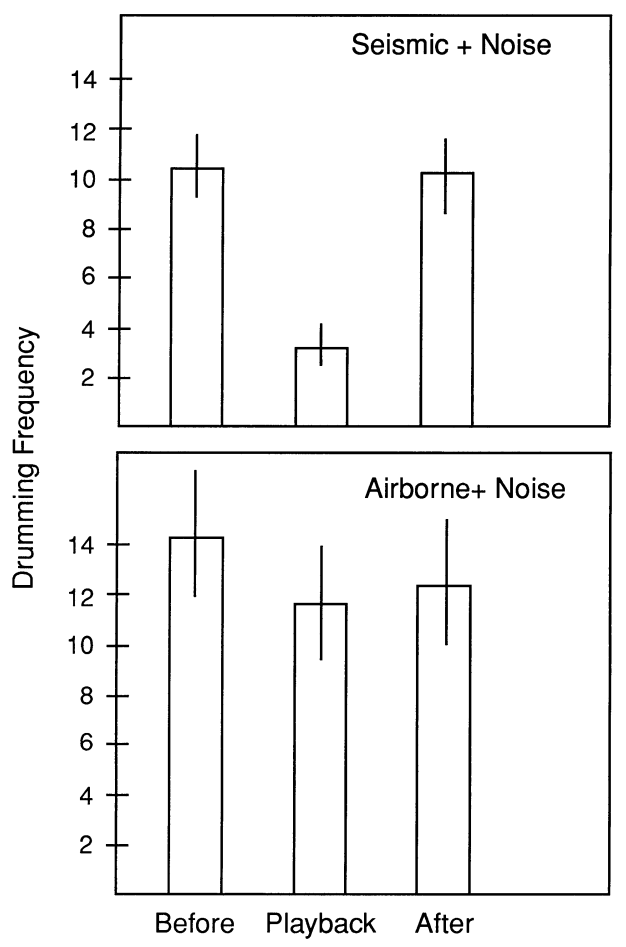

Fig. 3 Frequency of footdrumming sequences $(n=10)$ initiated during $7 \mathrm{~s}$ of playbacks of seismic footdrumming to the number initiated in the $7 \mathrm{~s}$ before and after the playback $(P<0.02)$ compared with footdrums initiated during and before and after airborne playbacks masked by noise $(n=5)(\mathrm{NS})$ 
transmitted through the ground must have been radiated by the chamber wall as airborne sound.

Results from the simulated burrow chamber support results from the rat burrows, especially those from the third rat chamber. The airborne thump sound was attenuated by $36 \pm 1 \mathrm{~dB}$ as it passed through the chamber wall. From a thumping site at a distance of $3.0 \mathrm{~m}$ from the simulated chamber, the peak acoustic power in the sound of the thump with accompanying seismic components was the same inside the chamber as outside. From the site $10 \mathrm{~m}$ from the simulated chamber, the peak acoustic power of the thump sound inside the chamber was only $4 \mathrm{~dB}$ less than it was outside the chamber. Thus, at both distances, at least $99.9 \%$ of the peak power in the thump sound in the chamber had been transmitted through the ground to the burrow chamber.

Our results indicate that when the banner-tailed kangaroo rat is in its underground chamber, with its entrance hole plugged, the vast majority (more than $99.9 \%$ ) of the power in the footdrum sounds that it hears has been transmitted directly through the ground from the footdrumming rat and then radiated through the walls of the chamber. Furthermore, the walls of the chamber provide good acoustic insulation from outside noise such as wind with an attenuation of airborne sound greater than $30 \mathrm{~dB}$ (power reduction greater than 1000 -fold). Thus, the sealed chamber provides a quiet place in which the rat can listen for substrate-borne communications from conspecifics. Virtually any sealed chamber (such as our simulated rat chamber) will provide the same features; and they should be available to fossorial and semi-fossorial animals in general.

\section{Communication}

Our results demonstrated that $D$. spectabilis can use the seismic channel for communication by footdrumming. The data imply that the rats were unable to hear the airborne thump sounds in the presence of noise inside the burrow chamber and thus were unable to time their own drumming patterns to the stimulus pattern. The rats soon ceased drumming during playbacks of the control, presumably because they could not hear drumming and were no longer stimulated to drum in return.

When the footdrumming reached $D$. spectabilis through the alternative, seismic, channel, the rats timed their drumming response so they did not drum over the drumming of the stimulus. They responded the same to footdrumming patterns transmitted seismically as they responded to the transmission of airborne footdrumming signals both in this study and in playback experiments (Randall 1994a). This behavior is similar to observed footdrumming behavior of the kangaroo rats in natural encounters. During footdrumming exchanges, a rat usually does not drum until the other rat stops (Randall 1984, 1994a). The rats transmit long-distance, airborne signals during footdrumming exchanges be- tween territories. Closer distance communication occurs when a rat enters the territory of another and drums on the mound in a territorial challenge or during mating (Randall 1984, 1991). In this case, the signal is probably both airborne and seismic. The sound outside the burrow is airborne and the sound inside the chamber would be substrate borne. At high population densities when territories are close together, the kangaroo rats can communicate underground between burrows (Randall 1984, 1995). In 1990, 40\% of the territories had a neighbor 9-10 $\mathrm{m}$ away and underground footdrumming exchanges between territories $10 \mathrm{~m}$ or less apart occurred.

The question remains, however, how an animal with an ear adapted to receive low-frequency, airborne sounds can perceive substrate vibrations transmitted through the ground. D. spectabilis has never been observed placing its head against a burrow or the ground to receive footdrumming signals, although there is a possibility they do this inside the burrow. As far as we know, these mammals have no specialized receptor for direct seismic reception as is found in anurans (Koyama et al. 1982; Narins and Lewis 1984). The best alternative explanation is that the kangaroo rats use their sensitive ear for airborne reception of low-frequency sound to hear the seismic signals when they become airborne in the burrow chamber. Audiograms reveal that kangaroo rats (D. merriami) possess excellent low-frequency hearing with a threshold of $50 \mathrm{~Hz}$ at $55 \mathrm{~dB}$ SPL (Webster and Webster 1972; Heffner and Masterton 1980). The lowest threshold could not be measured, so kangaroo rats probably hear even lower frequencies at $60 \mathrm{~dB}$ (Heffner and Masterton 1980). Sensitivity of the cochlear nucleus of D. spectabilis goes below $100 \mathrm{~Hz}$ (Moushegian and Rupert 1970). Our physical data show that sound enters the burrow chamber via the seismic channel $40 \mathrm{~dB}$ louder than sound entering from the air.

The ability to receive footdrumming signals via two channels affords kangaroo rats the opportunity to communicate by footdrumming both in and out of the burrow. They can communicate out of the burrow to distant neighbors via airborne sound on a windless night and in the burrow to close neighbors on windy nights. In burrow-dwelling mammals, both fossorial and semifossorial rodents exhibit adaptations to transmit and receive low-frequency, seismic vibrations. Among fossorial mammals, members of at least two families (Spalacidae and Bathyergidae) exhibit adaptations for generating and receiving low-frequency, seismic signals (Rado et al. 1987; Heth et al. 1991). Spalacid mole rats (S. ehrenbergi), for example, drum their heads against the ground. Although fossorial species such as these may exhibit an attenuated range of hearing in the higher frequencies and be less sensitive to sound with lower thresholds than other mammals (Heffner and Heffner 1990, 1992), S. ehrenbergi evidently enhances its ability to sense the head-drumming signals of a rat in a neighboring burrow by placing its jaw against the wall of its own burrow and invoking bone conduction to transmit 
the vibrations to its inner ear (Rado et al. 1989). Many semi-fossorial mammals have ears specialized for sensing low-frequency vibrations (Heffner et al. 1994). Modifications to the cochlea in the inner ear function in conjunction with middle ear specializations to result in a highly specialized hearing organ designed to detect lowfrequency airborne sounds (Petter 1961; Lay 1972, 1993; Webster and Webster 1984; Plassmann et al. 1987; Webster and Plassmann 1992).

The creation of sound by footdrumming occurs in a wide assortment of semi-fossorial rodents that inhabit open, arid environments (Randall 1994b). These rodents include the kangaroo rats, Dipodomys, in the family Heteromyidae from North America, and at least seven genera of gerbils (family Muridae, subfamily Gerbillinae) from north and south Africa, the Middle East and Eurasia (Randall 1993, 1994b). Gerbils and kangaroo rats footdrum in distinct, species specific footdrumming rhythms (Randall 1994b). The widespread use of footdrumming by desert rodents, coupled with the results of this study, suggest that semi-fossorial rodents have the flexibility to communicate to each other both above and below ground.

Acknowledgements We thank Dr. Ben Bonham for assisting with physical measurements and Eva Poinar and Ted Lai in data analysis. We are grateful to all the students who dug holes in the desert, carried equipment and tabulated data: Mary Beth Stone Green, Kim Duchare Litt, Evon Hekkala, Allie Rich, Jay Shore and Maureen Sullivan. We also thank the staff at the Southwestern Research Station. The experiments comply with NIH "Principles of Animal Care" and were approved by the University Animal Care and Use Committee. This research was supported by National Science Foundation grants BNS 89-08827 and BNS 91-09850 to J.A. Randall and UC-Berkeley Committee on Research Grant and DC-00112 from the National Institute of Deafness and Communicative Disorders to E.R. Lewis.

\section{References}

Baurecht D, Barth FG (1992) Vibratory communication in spiders. I. Representation of male courtship signals by female vibration receptor. J Comp Physiol A 171: 231-243

Cortopassi KA, Lewis ER (1992) Further evidence of seismic communication in the white-lipped frog. Proc 3rd Int Congr Neuroethol, p 150

Heffner H, Masterton B (1980) Hearing in Gilres: domestic rabbit, cotton rat, feral house mouse and kangaroo rat. J Acoust Soc Am 68: 1584-1599

Heffner RS, Heffner HE (1990) Vestigial hearing in a fossorial mammal, the pocket gopher (Geomys busarius). Hearing Res 46:239-252

Heffner RS, Heffner HE (1992) Hearing and sound localization in blind mole rats (Spalax ehrenbergi). Hearing Res 62:206-216

Heffner RS. Heffner HE, Contos C, Kearns D (1994) Hearing in prairie dogs: transition between surface and subterranean rodents. Brain Res 73:185-189

Heth G, Frankenberg G, Raz A, Nevo E (1987) Vibrational communication in subterranean mole rats (Spalax ehrenbergi). Behav Ecol Sociobiol 21:31-33

Heth G, Frankenberg H, Pratt H, Nevo E (1991) Seismic communication in the blind subterranean mole-rat: patterns of head thumping and their detection in the Spalax ehrenbergi superspecies in Israel. J Zool 224:633-638
Jarvis JUM, Bennett NC (1991) Ecology and behavior of the family Bathyergidae. In: Sherman PW, Jarvis JUM, Alexander RD (eds) The biology of the naked molerat. Princeton University Press, Princeton, New Jersey, pp 66-96

Koyama H, Lewis ER, Leverenz EL, Baird RA (1982) Acute seismic sensitivity in the bullfrog ear. Brain Res 250:168-172

Lay DM (1972) The anatomy, physiology, functional significance and evolution of specialized hearing organs of Gerbilline rodents. J Morphol 138:41-120

Lay DM (1993) Anatomy of the heteromyid ear. In: Genoways $\mathrm{HH}$, Brown JH (eds) Biology of the Heteromyidae. American Society of Mammalogists, Shippenburg, Pennsylvania, pp 270 290

Lewis ER, Narins PM (1985) Do frogs communicate with seismic signals? Science 227:187-189

Markl H (1983) Vibrational communication. In: Huber F, Markl H (eds) Neuroethology and behavioural physiology. Springer, Berlin Heidelberg New York, pp 332-353

Moushegian G, Rupert AL (1970) Responses diversity of neurons in ventral cochlear nucleus of kangaroo rat to low-frequency tones. J Neurophysiol 33:351-364

Narins PM (1990) Seismic communication in anuran amphibians. Bioscience 40:268-274

Narins PM, Lewis ER (1984) The vertebrate ear as an exquisite seismic sensor. J Acoust Soc Am 76:1384-1387

Narins PM, Reichman OJ, Jarvis JUM, Lewis ER (1992) Seismic signal transmission between burrows of the cape mole-rat, $\mathrm{Ge}$ orychus capensis. J Comp Physiol A 170:13-21

Petter F (1961) Enlargement of the tympanic bullae among desert rodents. Mammalia 25:187-219

Plassmann W, Peetz W, Schmidt M (1987) The cochlea in gerbilline rodents. Brain Behav Evol 30:82-101

Pratte M, Jeanne RL (1984) Antennal drumming behavior in $\mathrm{Po}$ listes wasps (Hymenoptera: Vespidae). Z Tierpsychol 66:177188

Rado R, Levi N, Hauser H, Witcher J, Adler N, Intrator N, Wollberg Z, Terkel J (1987) Seismic signalling as a means of communication in a subterranean mammal. Anim Behav 35:1249-1266

Rado R, Himelfarb M, Arensburg B, Terkel J, Wollberg Z (1989) Are seismic communication signals transmitted by bone conduction in the blind mole rat? Hear Res 41:23-30

Randall JA (1984) Territorial defense and advertisement by footdrumming in bannertail kangaroo rats (Dipodomys spectabilis) at high and low population densities. Behav Ecol Sociobiol 16:11-20

Randall JA (1989) Individual footdrumming signatures in bannertailed kangaroo rats, Dipodomys spectabilis. Anim Behav 38:620-630

Randall JA (1991) Mating strategies of a nocturnal desert rodent, Dipodomys spectabilis. Behav Ecol Sociobiol 28:215-220

Randall JA (1993) Behavioral adaptations of desert rodents (Heteromyidae). Anim Behav 45:263-287

Randall JA (1994a) Discrimination of footdrumming signatures by kangaroo rats, Dipodomys spectabilis. Anim Behav 47:45-54

Randall JA (1994b) Convergences and divergences in communication and social organisation of desert rodents. Aust J Zool 42:405-433

Randall JA (1995) Modification of footdrumming signatures by kangaroo rats: changing territories and gaining new neighbours. Anim Behav 49:1227-1237

Randall JA, Matocq MD (1997) Why do kangaroo rats (Dipodomys spectabilis) footdrum at snakes? Behav Ecol (in press)

Webster DB, Plassmann W (1992) Parallel evolution of low-frequency sensitivity in old world and new world desert rodents. In: Fay RR, Popper AN (eds) The evolutionary biology of hearing. Springer, Berlin Heidelberg New York, pp 633-636

Webster DB, Webster M (1972) Kangaroo rats auditory thresholds before and after ear reduction. Brain Behav Evol 5:41-53

Webster DB, Webster M (1984) The specialized auditory system of kangaroo rats. Sens Physiol 8:161-196 